\title{
A correlative isotopic and histological study of soleal vein thrombosis
}

\author{
RICHARD WRAY, D. RIMMER, M. DENHAM, AND E. B. RAFTERY
}

From Northwick Park Hospital, Harrow, Middlesex

SYNOPSIS Thirteen patients are described in whom the results of ${ }^{125}$ I fibrinogen uptake testing in life were compared with the postmortem findings in the soleus muscle and in addition with direct radioactive counting of soleus muscle portions. The sensitivity of the ${ }^{125}$ I fibrinogen uptake test was found to be approximately half that of direct muscle radioactive counting or histological examination. Some limitations of the technique are discussed.

The ${ }^{125}$ I fibrinogen uptake test is now widely used for the diagnosis of calf vein thrombosis in clinical practice. Since its introduction by Atkins and Hawkins (1965) and subsequent modification by Negus, Pinto, Lequesne, Brown, and Chapman (1968), the incidence of calf vein thrombosis in a number of clinical situations has been established (Flanc, Kakkar, and Clarke, 1968; Friend and Kakkar, 1970; Field, Kakkar, Nicolaides, and Renney, 1971; Maurer, Wray, and Shillingford, 1971; Nicolaides, Field, Kakkar, Yates-Bell, Taylor, and Clarke, 1972). Validation of the technique in man has largely depended upon venographic examination of the lower limbs below the inguinal ligament revealing thrombus in cases with a positive ${ }^{125}$ I fibrinogen uptake test (Negus et al, 1968).

In the present study a different method of validation is reported. Gibbs (1957), in exhaustive postmortem dissection studies, noted that calf muscle thrombus was most commonly found within the soleus muscle. It was therefore decided to study whether the results of the ${ }^{125}$ I fibrinogen uptake test in life could be correlated with both radioactive counting of central portions of the soleus muscle and close examination of the soleus veins at necropsy. These studies show that with certain limitations there is close correlation between the results obtained in vivo and in vitro.

\section{Materials and Methods}

The ${ }^{125}$ I fibrinogen uptake test is used routinely in the cardiac and geriatric units at Northwick Park Hospital for patients confined to bed who are thought

Received for publication 5 August 1974. likely to develop significant venous thrombosis. Between August 1972 and June 1973 the soleus muscles of 13 patients who died during this period were removed and studied in detail. All these patients had previously received ${ }^{125}$ I fibrinogen, in most cases shortly after admission. Anticoagulant therapy was not used. There were eight men and five women in this series with an age range of 57 to 83 years. Further information concerning each case is given in table I. The postmortem procedure adopted was as follows. The soleus muscles were removed proximally at their medial and lateral bony attachments and distally at the commencement of the Achilles tendon. The overlying gastrocnemius muscle was removed. Each muscle was laid with the superficial aspect uppermost and sliced transversely into six portions. Two paracentral longitudinal cuts were then made, thus providing from each soleus muscle six blocks of tissue, a portion of each, of 3 to $4 \mathrm{~g}$ weight being taken after weighing (to the nearest $0.1 \mathrm{~g}$ ) for radioactive counting. Proximal portions from each soleus muscle were labelled 1 and distal portions labelled 6 (table IV).

Each portion of soleus muscle after macroscopic examination was placed in a plastic tube of $10 \mathrm{ml}$ capacity containing approximately $1 \mathrm{ml}$ of formalin. The tubes were transferred with minimum delay to an LKB Wallac automatic gamma emission counter set to record both background and sample radioactive counts. A 1000 second counting period was used with an upper limit of 10000 counts for each specimen and the results were printed out automatically.

All muscle portions were examined histologically (except case 2). Sections were stained with haematoxylin and eosin, and examined to establish the 


\begin{tabular}{|c|c|c|c|c|c|c|c|}
\hline Case & Age & $\begin{array}{l}\text { Duration of } \\
\text { Bed Rest } \\
\text { (days) }\end{array}$ & $\begin{array}{l}\text { Exposure Period } \\
\text { to }{ }^{12.5} / \\
(d a y s)\end{array}$ & $\begin{array}{l}\text { Venous } \\
\text { Thrombosis }\end{array}$ & $\begin{array}{l}\text { Pulmonary } \\
\text { Embolism }\end{array}$ & $\begin{array}{l}\text { Pulmonary } \\
\text { Infarction }\end{array}$ & Postmortem Diagnosis \\
\hline 1 & 78 & 12 & 11 & . & $\rightarrow$ & - & Carcinoma bronchus \\
\hline 2 & 76 & 5 & 4 & - & -. & - & Anterior myocardial infarction \\
\hline 3 & 57 & 14 & 10 & - & - & - & Anterior myocardial infarction \\
\hline 4 & 66 & 25 & 24 & - & - & - & Anterior myocardial infarction \\
\hline 5 & 61 & 3 & 2 & - & - & - & Anterior myocardial infarction \\
\hline 6 & 67 & 8 & 6 & - & - & - & Anterior myocardial infarction \\
\hline 7 & 70 & 11 & 10 & . & - & - & Cerebrovascular disease \\
\hline 8 & 74 & 28 & 2 & . & - & - & Bronchopneumonia \\
\hline 9 & 78 & 7 & 6 & . & 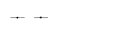 & - & Cerebrovascular disease \\
\hline 10 & 70 & 6 & 4 & & - & - & Carcinomatosis \\
\hline 11 & 83 & 15 & 15 & . &. & - & Cerebrovascular disease \\
\hline 12 & 66 & 7 & 7 & .. & - & $\ldots$ & Congestive heart failure \\
\hline 13 & 59 & 27 & 23 & - & - & - & Uraemia, myocardial infarction \\
\hline
\end{tabular}

Table I Individual case details for 13 patients

presence or absence of structured antemortem thrombus in large veins greater than $2 \mathrm{~mm}$ in diameter and in small veins less than $1 \mathrm{~mm}$ in diameter. The presence of thrombus was confirmed by staining sections with martius scarlet blue to demonstrate fibrin (Lendrum, Fraser, Slidders, and Henderson, 1962).

The ${ }^{125}$ I fibrinogen uptake test employed depends on the uptake of fibrinogen, a small proportion of which is labelled with radioactive iodine, into forming clot and its subsequent detection by increasing radioactive counts over the site of the clot. The ${ }^{125}$ I was obtained from the Radiochemical Centre, Amersham, England and attached in optimal proportion to fibrinogen obtained from donors known to be hepatitis $\mathrm{B}$ antigen negative. The shelf life of ${ }^{125}$ I fibrinogen prepared in this manner is approximately 60 days and the biological half life after intravenous injection $3 \cdot 1$ days (Jeyasingh, Maurer, Rosengarten, and Verma, 1970). Surface radioactive counts were recorded with a J \& P portable scintillation counter as previously described (Flanc et al, 1968; Maurer et al, 1971) and the results interpreted according to the criteria originally proposed by Negus et al (1968). It was suggested by these workers that an increase in percentage uptake of 15 which persisted and continued to rise between adjacent points on the same limb or a corresponding point on the opposite limb was diagnostic of thrombus formation.

The term 'venous thrombosis' in this article, unless otherwise stated, refers to the presence of thrombus in soleus muscle veins.

\section{Results}

Venous thrombosis was present in the soleus muscle at necropsy in seven of the 13 patients studied and associated with macroscopic pulmonary embolism in five patients (table I). None of the five patients admitted with myocardial infarction showed evi- $\vec{\circ}$ dence of venous thrombosis although one had a pulmonary embolus (case 2 ). In only one patient $\vec{\omega}$ was pulmonary embolism the cause of death (case 9) and in only one patient (case 12) was there evidence of pulmonary infarction resulting from pulmonary embolism. Five patients had bilateral soleal vein thrombosis and a further two patients had evidence of unilateral macroscopic amd microscopic venous thrombosis respectively (table II: cases 11 and 7).

A positive ${ }^{125}$ I fibrinogen uptake test was noted i cases $1,9,10$, and 11 (case 8 was excluded since the test was not performed). There were no false positive results. A comparison of ${ }^{125}$ I fibrinogen uptake testing in life with postmortem findings in soleus muscle veins of each limb is shown in table III (case 8 excluded). Negative ${ }^{125}$ I fibrinogen uptake tests were obtained in the presence of soleus thrombus in one limb in cases 7 and 9 and in both limbs in case 12 .

Soleus muscle radioactive counts were higher than expected in all patients with soleus vein thrombus at necropsy (tables II and IV). In case 2 radioactive counts from the left soleus muscle were significantly higher than those from the right soleus muscle and were associated with pulmonary embolism, although the soleus muscle postmortem examination was normal and the 125I fibrinogen uptake test was negative. In case 7 a small area of microscopic venous thrombosis was associated with a localized increase in radioactive counts although the ${ }^{125} I$ fibrinogen uptake test was negative. Total radioactive counts were reduced beyond the expected value in case 7 . Pulmonary embolism was present in case 7. Case 9 demonstrated clear postmortem evidence of venous thrombosis, and radioactive 0 counts were raised in both limbs although the right soleus muscle counts were significantly $(\mathrm{P}<0.001)$ increased compared with those from the left soleus muscle. A positive ${ }^{125}$ I fibrionogen uptake test was recorded in the right calf alone in case 9 . In case 12 


\begin{tabular}{|c|c|c|c|c|c|c|c|}
\hline \multirow[t]{3}{*}{ Case } & \multirow{3}{*}{$\begin{array}{l}{ }^{125} \text { I Fibrinogen } \\
\text { Exposure Period } \\
\text { in Days }\end{array}$} & \multicolumn{6}{|c|}{ Postmortem Examination } \\
\hline & & \multicolumn{3}{|c|}{ Right Soleus Muscle } & \multicolumn{3}{|c|}{ Left Soleus Muscle } \\
\hline & & Macro & Micro $>2 \mathrm{~mm}$ & Micro $<1 \mathrm{~mm}$ & Macro & Micro $>2 \mathrm{~mm}$ & Micro $<\operatorname{Imm}$ \\
\hline 8 & 2 & +1 & + & - & + & + & - \\
\hline 5 & 2 & - & - & - & - & - & - \\
\hline 2 & 4 & - & $(-)$ & $(-)$ & - & $(-)$ & $(-$ \\
\hline 10 & 4 & + & + & - & + & + & - \\
\hline 6 & 6 & - & - & - & - & - & - \\
\hline 9 & 6 & + & + & - & + & + & - \\
\hline 12 & 7 & + & + & - & + & + & - \\
\hline 1 & 11 & + & + & - & + & + & - \\
\hline 3 & 10 & - & - & - & - & - & - \\
\hline 7 & 10 & - & - & - & - & + & - \\
\hline 11 & 15 & - & - & - & + & + & - \\
\hline 4 & 24 & - & - & - & - & - & - \\
\hline 13 & 23 & - & - & - & - & - & - \\
\hline
\end{tabular}

Table II Postmortem soleus muscle examination for venous thrombosis

+ indicates thrombus present; - thrombus absent; $(-)$ histology not available in 13 patients

\begin{tabular}{|c|c|c|c|}
\hline & \multicolumn{2}{|c|}{ Postmortem Examination } & \multirow[t]{2}{*}{ Total } \\
\hline & $\begin{array}{l}\text { Venous } \\
\text { Thrombus } \\
\text { Present }\end{array}$ & $\begin{array}{l}\text { Venous } \\
\text { Thrombus } \\
\text { Absent }\end{array}$ & \\
\hline \multirow{2}{*}{$\begin{array}{l}125 \text { I fibrinogen uptake test } \\
\text { positive } \\
{ }_{125} \text { I fibrinogen uptake test } \\
\text { negative }\end{array}$} & 6 & 0 & 6 \\
\hline & 4 & 14 & 18 \\
\hline Totals & 10 & 14 & 24 \\
\hline
\end{tabular}

Table III Comparison between soleus muscle examination for venous thrombosis and the results of the ${ }^{125} I$ fibrinogen uptake test during life in 12 patients (case 8 excluded)

$x^{2}-11.1996 \quad \mathrm{r}=0.5640 \quad \mathrm{P}<0.001$

there was extensive postmortem venous thrombosis and radioactive counts from the soleus muscle were significantly increased $(P<0.001)$ compared with the control value (table IV, case 6). The ${ }^{125}$ I fibrino- gen uptake test was, however, negative. Total radioactive counts from each soleus muscle in this series were in accord with postmortem findings in all cases. In case 7 the total dose of radioactivity administered was measured at approximately $100 \mu \mathrm{Ci}$ but in spite of this low counts were recorded at necropsy 10 days later. The ${ }^{125}$ I fibrinogen uptake test was positive in $25 \%$ of 24 limbs in this series; postmortem soleal vein thrombus was detected in $46 \%$ of 26 limbs and radioactive muscle portion counting was in keeping with a diagnosis of thrombus accumulation in $54 \%$ of the 26 limbs. The sensitivity of the ${ }^{125}$ I fibrinogen uptake test is thus approximately half that of direct muscle studies in the detection of venous thrombosis. In table II cases are grouped according to the 125I fibrinogen exposure period, which approximates to the duration of bed rest in all except case 8, to show that in this series soleus muscle venous: thrombus was not more frequent with increasing duration of bed rest.

\begin{tabular}{|c|c|c|c|c|c|c|c|c|c|c|c|c|c|}
\hline \multirow[t]{2}{*}{ Case } & \multirow{2}{*}{$\begin{array}{l}{ }^{25} \text { I Fibrinogen } \\
\text { Exposure Period } \\
\text { in Days }\end{array}$} & \multicolumn{6}{|c|}{ Right Soleus Muscle } & \multicolumn{6}{|c|}{ Left Soleus Muscle } \\
\hline & & 1 & 2 & 3 & 4 & 5 & 6 & 1 & 2 & 3 & 4 & 5 & 6 \\
\hline 1 & 11 & 80 & 178 & 101 & 658 & 78 & 66 & 2253 & 4342 & 7519 & 1179 & 273 & 62 \\
\hline 2 & 4 & 375 & 322 & 526 & 407 & 428 & 290 & 927 & 897 & 596 & 1052 & 1157 & 324 \\
\hline 3 & 10 & 589 & 538 & 579 & 509 & 564 & 519 & 490 & 475 & 505 & 463 & 546 & 531 \\
\hline 4 & 24 & 86 & 76 & 62 & 69 & 72 & 88 & 190 & 88 & 76 & 58 & 52 & 75 \\
\hline 5 & 2 & 902 & 907 & 831 & 847 & 919 & 1150 & 998 & 1018 & 1125 & 1134 & 1480 & 1157 \\
\hline 6 & 6 & 279 & 380 & 399 & 400 & 394 & 360 & 1065 & 1007 & 907 & 991 & 877 & 972 \\
\hline 7 & 10 & 54 & 9 & 9 & 16 & 8 & 8 & 11 & 10 & 17 & 61 & 1013 & 30 \\
\hline 8 & 2 & 2138 & 2283 & 2152 & 3169 & 1803 & 1726 & 2213 & 2436 & 2522 & 2433 & 2744 & 2161 \\
\hline 9 & 6 & 519 & 691 & 5030 & 1453 & 1094 & 189 & 43 & 174 & 673 & 45 & 57 & 42 \\
\hline 10 & 4 & 6410 & 3283 & 7200 & 3608 & 6778 & 4274 & 2668 & 2219 & 1115 & 3690 & 985 & 3287 \\
\hline 11 & 15 & 236 & 232 & 236 & 253 & 241 & 226 & 944 & 2011 & 2807 & 2080 & 1858 & 502 \\
\hline 12 & 7 & 1295 & 1363 & 2657 & 1085 & 1680 & 1168 & 1947 & 2049 & 1961 & 1174 & 1065 & 1195 \\
\hline 13 & 23 & 110 & 152 & 113 & 190 & 110 & 136 & 167 & 149 & 141 & 175 & 171 & 134 \\
\hline
\end{tabular}

Table IV Radioactive counts from soleus muscle blocks in 13 patients who received ${ }^{125}$ I fibrinogen during life ${ }^{1}$ ${ }^{1}$ Counts/gram wet weight/1000 seconds 


\section{Discussion}

The incidence of postmortem venous thrombosis in published series varies between 29 and $52.7 \%$ (Hunter, Sneeder, Robertson, and Snyder, 1941; Raeburn, 1951; Gibbs, 1957; Sevitt and Gallagher, 1959). The incidence of venous thrombosis in this present study is in accord with the results obtained by Hunter et al (1941). Postmortem examination of the lower limb veins of patients with a positive ${ }^{125} \mathrm{I}$ fibrinogen uptake test were reported by Nanson, Palko, Dick, and Fedoruk (1965), Flanc et al (1968) and Browse, Clapham, Croft, Jones, Thomas, and Williams (1971). Antemortem thrombus was present in each case. Detailed study of the soleus muscles was not performed. Negus et al (1968) reported that four patients with negative ${ }^{125}$ I fibrinogen uptake tests who subsequently died showed no evidence of antemortem venous thrombosis. Close correlation between histological and surface isotopic evidence of venous thrombosis in the present study occurred when there was extensive involvement of the soleus muscle. The sensitivity of the ${ }^{125}$ I fibrinogen uptake test in this series of 13 patients has been established at approximately half that of direct muscle radioactive counting or histological examination. The negative ${ }^{125}$ I fibrinogen uptake test in case 12 is of interest since extensive venous thrombosis was present. Combined venographic and ${ }^{125}$ I fibrinogen uptake studies in 102 cases were reported by Browse et al (1971) to be in agreement in $90 \%$ of cases; false negative ${ }^{125}$ I fibrinogen uptake tests were noted in $10 \%$. It is of clinical importance that Mavor, Mahaffy, Walker, Duthie, Dhall, Gaddie, and Reid (1972) showed that by the time significant thromboembolism occurred (usually from the ileofemoral segment) the ${ }^{125}$ I fibrinogen uptake test was positive in only 30 to $36 \%$ of cases.

Our recommendation regarding the ${ }^{125}$ I fibrinogen uptake test is that undue emphasis should not be given to negative results obtained from calf radio- active counting in patients previously confined to bed.

Our thanks are due to Dr N. Veall, Dr G. Slavin, Dr Helen Farran, and Mrs Gloria James for encouragement and practical help during this study.

References

Atkins, P., and Hawkins, L. A. (1965). Detection of venous thrombosis in the legs. Lancet, 2, 1217-1219.

Browse, N. L., Clapham, W. F., Croft, D. N., Jones, D. J., Thomas, M. L., and Williams, J. O. (1971). Diagnosis of established deep vein thrombosis with the ${ }^{125} \mathrm{I}$ fibrinogen uptake test. Brit. med. J., 4, 325-328.

Field, E. S., Kakkar, V. V., Nicolaides, A. N., and Renney, J. T. G. (1971). Deep vein thrombosis in patients with fractured neck of femur. Brit. J. Surg., 58, 873.

Flanc, C., Kakkar, V. V., and Clarke, M. B. (1968). The detection of venous thrombosis of the legs using ${ }^{125} \mathrm{I}$-labelled fibrinogen.

Brit. J. Surg., 55, 742-747.
Friend, J., and Kakkar, V. V. (1970). The diagnosis of deep vein $\mathrm{N}$ thrombosis in the puerperium. J. Obstet. Gynaec. Brit. Cwlth, $\overrightarrow{\vec{\theta}}$ $77,820-823$

Gibbs, N. M. (1957). Venous thrombosis of the lower limbs with $\infty$ particular reference to bed-rest. Brit. J. Surg., 45, 209-236.

Hunter, W. C., Sneeden, V. D., Robertson, T. D., and Snyder, G. A. C. (1941). Thrombosis of the deep veins of the leg. Arch. intern. Med., 68, 1-17.

Jeyasingh, K., Maurer, B., Rosengarten, D. S., and Verma, T. R. (1970). Decline in blood activity of ${ }^{125} \mathrm{l}$-fibrinogen in venous thrombosis. Lancet, 2, 294-296.

Lendrum, A. C., Fraser, D. S., Slidders, W., and Henderson, R. (1962). Studies of the character and staining of fibrin. J. clin. Path., 15, 401-413.

Maurer, B. J., Wray, R., and Shillingford, J. P. (1971). Frequency of venous thrombosis after myocardial infarction. Lancet, $\triangle$ 1385-1387.

Mavor, G. E., Mahaffy, R. G., Walker, M. G., Duthie, J. S., Dhał D. P., Gaddie, J., and Reid, G. F. (1972). Peripheral venot scanning with ${ }^{125}$ I-tagged fibrinogen. Lancet, 1, 661-663.

Nanson, E. M., Palko, P. D., Dick, A. A., and Fedoruk, S. O. (1965). Early detection of deep venous thrombosis of the legs using $I^{131}$ tagged human fibrinogen: a clinical study. Ann. Surg., 162, 438-445.

Negus, D., Pinto, D. J., Lequesne, L. P., Brown, N., and Chapman, M. (1968). ${ }^{125}$ I labelled fibrinogen in the diagnosis of deep vein thrombosis and its correlation with phlebography. Brit. J. Surg., 55, 835-839.

Nicolaides, A. N., Field, E. S., Kakkar, V. V., Yates-Bell, A. J., Taylor, S., and Clarke, M. B. (1972). Prostatectomy and deepvein thrombosis. Brit. J. Surg., 59, 487-488.

Raeburn, C. (1951). The natural history of venous thrombosis. Brit. med. J., 2, 517-520.

Sevitt, S., and Gallagher, N. G. (1959). Prevention of venous thrombosis and pulmonary embolism in injured patients. Lancet, 2, 981-989. 